\title{
Co-design open-source medical devices: how to minimize the human error using UBORA e-infrastructure*
}

\author{
Licia Di Pietro, Carmelo De Maria, Alice Ravizza, Arti Ahluwalia
}

\begin{abstract}
In the complex context of the medical device industry and healthcare systems, the reduction in cost may increase access to medical technologies moving towards global health equity. This paper is focused on the description of UBORA, an e-infrastructure based on a new concept of biomedical engineering which promotes the open-source approach for co-designing medical devices, fostering innovative ideas, needs-based, low-cost and safe technology. UBORA structures the entire design process using EN ISO 13485:2016, standard related to medical technology for inspiration. As a proof of concept, this paper shows an example of the development of an open source medical device for hand rehabilitation, designed using UBORA. We demonstrate the straightforward pathway to gather information on safety requirements. Finally, we describe a usability test of the einfrastructure performed during the $4_{\text {th }}$ WHO Global Forum on Medical Devices in India.
\end{abstract}

\section{INTRODUCTION}

Health is a fundamental aspect of quality of life. Technology plays a fundamental role in improving the quality of health, being the fulcrum of an effective healthcare system. The 2030 Agenda for Sustainable Development Goals (SDGs), adopted by all United Nations Member States, clearly emphasizes the impact of the lack of appropriate medical devices (MDs) on health conditions [1][2].

There is no doubt that patients and healthcare providers in low-income countries (LICs) have limited access to MDs and this is due to several reasons [3]. One barrier for the accessibility of medical technologies includes the high costs of imported MDs. Developing countries often lack funds to address their needs and the cost of MDs can be prohibitive for small clinics and hospitals. In some developing countries, World Health Organization (WHO) estimates that more than $80 \%$ of medical equipment is donated [4], but only $10-30 \%$ of these become operational [5]. Medical equipment is largely manufactured in developed countries and it has been designed to operate in clean, sterile, climate-controlled environment, with reliable electricity. However, in LICs, MDs are subjected to harsh environment conditions, extreme climate conditions, humidity, dust and power instability. These conditions cause more frequent failures and determine a higher request for spare parts, which are expensive and difficult to find, making maintenance and repairing as problematic as acquisition [6]. Furthermore, many imported devices require specialized

\footnotetext{
*This project has received funding from the European Union's Horizon 2020 research and innovation programme under grant agreement $\mathrm{N}^{\circ} 731063$.

Licia Di Pietro is a Ph.D. Student at the Department of Information Engineering, University of Pisa, Pisa, 56126, ITALY (phone: +393289670252; e-mail: licia.dipietro@ing.unipi.it).

Carmelo De Maria is an Assistant Professor at the Department of Information Engineering, University of Pisa, and affiliated with the Research
}

personnel, often unavailable on site, and the machines remain unused for months [7][8].

\section{CONCEPT AND APPROACH}

Developing sustainable technologies to reduce global inequalities can only be performed taking into account the cultural and socio-economic context in which these will be applied [9]. The cost reduction may help to make healthcare affordable to a larger population, a key process towards health equity [10].

Compared to the traditional methods of design, the opensource approach can be a possible alternative. By definition, open-source means making the design, documentation, source-code, blueprints, ideas and results available for the public. Having the software, electronic and hardware design available under an open-source license allows anyone to study, modify, improve and contribute to the design potentially leading to very rapid innovation [11].

The application of the open-source approach to MD design has been proved to offer a unique combination of advantages, such as increasing safety, security, robustness and reducing costs [12]. Until a few years ago the development of MDs was essentially linked to companies and universities, but recently several examples of open-source MDs (OSMDs) have appeared on the web [13]. However only some of them have been designed to be compliant with MD legislation [14-16].

It is crucial to ensure the safety and efficacy requirements of medical technology and for this reason the adoption of open resources must follow the standards and current regulations [17]. To this end, a new e-infrastructure, UBORA ("excellence" in Swahili) [18] which fuses the open source concepts with the safety and efficacy requirements of medical technology has recently been established. UBORA (EuroAfrican open Biomedical Engineering e-platform for Innovation through Education) was funded by the EU's H2020 programme (Fig. 1).

Its objective is to support open source co-design of new solutions to face the current and future healthcare challenges of Europe and Africa, by exploiting networking, knowledge on rapid prototyping of new ideas and sharing of safety criteria and performance data [19]. UBORA's safety references are based on the EU Regulation on MDs (MDR) 2017/745 [20],

Center "Enrico Piaggio", Pisa, 56126, ITALY (e-mail: carmelo.demaria@unipi.it).

Alice Ravizza is a founder USE-ME-D @I3P, an innovative start-up at Polytechnic University of Turin, Turin, 10129, ITALY (e-mail: alice.ravizza@use-me-d.com)

Arti Ahluwalia is a Full Professor at the Department of Information Engineering, University of Pisa, and Director of the Research Center "Enrico Piaggio”, Pisa, 56126, ITALY (e-mail: arti.ahaluwalia@unipi.it). 
as it is considered one of the most advanced regulation systems in the world [21][22]. It imposes strict controls and refined requirements to more effective devices, ensuring their traceability throughout Europe. The EU MDR requires implementing a comprehensive Quality Management System (QMS), and most companies meet this requirement following the harmonized (i.e. EU approved) standard EN ISO 13485:2016 Medical devices - Quality management systemRequirements for regulatory purpose certification which specifies requirements for all entities involved in the life-cycle of a MD [23].

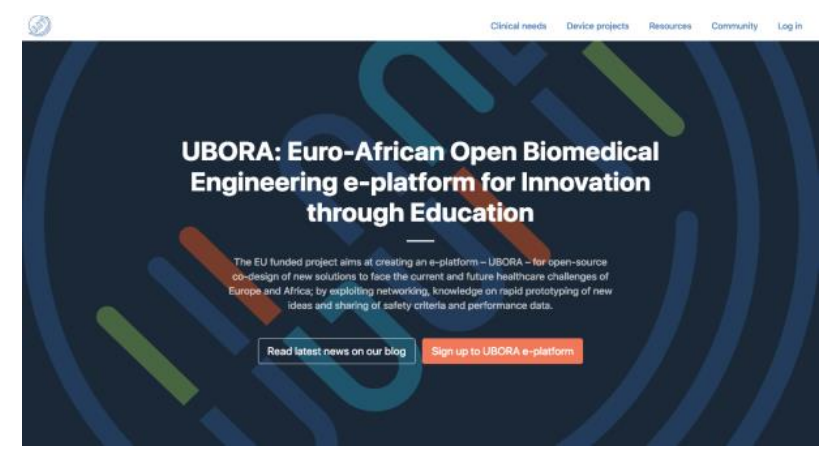

Figure 1. Landing page of the UBORA e-infrastructure [21]

The purpose of this paper is to describe the method of codesign of OSMDs through the UBORA e-infrastructure, where the design planning and the structure are inspired by the EN ISO 13485:2016 for respecting the standards related to the development of medical technology in view of minimizing human error during the design process.

\section{UBORA E-PLATFORM IMPLEMENTATION}

UBORA promotes and sustains the OSMDs development, providing a structured framework for the identification of needs, risk class, relevant standards, management of computer-aided modeling files and preparation of the preproduction device dossier. Each stage is vetted and monitored by experts to ensure that safety criteria are met during the design process. The e-infrastructure is organized in 3 main sections described below.

- Clinical needs: aimed at identifying bioengineering design specifications linked to a particular clinical need. To create safety and impactful medical solutions, this section is the most unique. It provides an environment for healthy discussion between patients, healthcare providers and engineers to ensure that needs are turned into projects that are safe, affordable and user friendly.

- Project management: opened to users to design MDs under the coordination of BME professionals (mentors). It is a MD oriented project management environment, including a repository, available for free download of project blueprints which have completed the development and compliance phase.

- Resource section: with selected teaching/learning materials on BME.

Only after vetting by a team of BME experts, who assess the device project, can it be downloaded by external users. All the information, including the performance and safety documentation data, as well as the instructions for the calibration and maintenance, are available for the platform users.

The Project management section passes through 6 Work Packages (WPs) shown in Fig. 2 and described below in more detail.

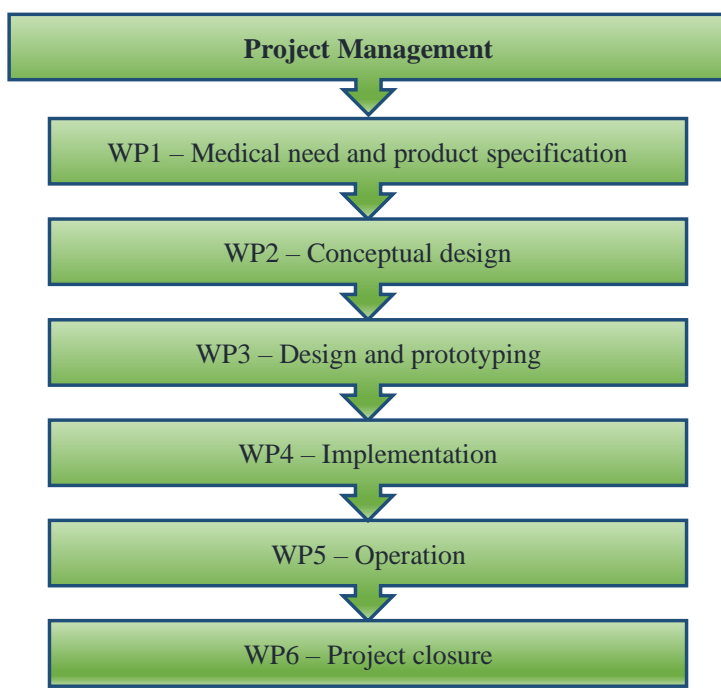

Figure 2. WPs for project development using the UBORA e-infrastructure

The medical need and product specification section (WP1) is designed in order to specify the clinical need and identify the main product requirements, as well as clinical area related to the technology. Keywords for indexing the project are also established. Moreover, in WP1, the risk class and applicable standards for the specific design are identified. The device classification, structured through a checklist, follows the rules described in Annex VIII of MDR 2017/745 [20]. In order to improve usability and minimize human error, the rules are arranged as a decision tree, which leads the designer(s) through a flow of simple (mainly yes/no) questions. As mentioned in the MDR 2017/745, Chapter 1, Article 8, the devices that are in conformity with the harmonised standards shall be presumed to be compliant with the current regulation [20]. Regarding the applicable standards to the device, UBORA provides a list of questions regarding the medical technology in order to select the basic safety standards (also known as horizontal standards), which are usually difficult to identify through keywords in a search engine.

WP2 leads the designer in the development of different embodiments/ideas of the same MD, which will be analysed and ranked in a polling section, on the basis of feasibility, performance, usability and safety aspects. Through WP3 for design and prototyping, the designer prepares documents related to the MD idea proposed in WP2: the project management system suggests the organization in subsections related to mechanical components, electronics/firmware, software, and their integration. Once WP3 is concluded, WP4 leads the developers in the testing phase to demonstrate the compliance with relevant standards. WP5 is devoted completing the technical documentation of the device in order to publish the project for downloading and potentially transfer the technology to industry ensuring its compliance with the EU MDR. Finally, WP6 guides the developers in creating 
promotional videos and brochures, toward a possible crowdfunding campaign.

UBORA was officially launched to the public in September 2018. To date the e-infrastructure has 485 users, 286 projects and numerous case studies.

\section{CASE Study: Hand ReHabilitation dEVICE}

We selected an OSMD available on the UBORA einfrastructure to contextualize and evaluate the innovative action of UBORA to design appropriate open source technologies.

"Hand of Elderly Rehabilitation Open-source" (HERO, Fig. 3) is a muscular rehabilitation device with the aim of increasing the force developed by the hand and fingers. Based on a clinical need and selected through an online poll in WP2 of UBORA from 4 different conceptual designs, it consists of a stretchable membrane made of silicon (see Fig. 3a) (Dragon Skin® 10 Fast, Smooth-on, Inc, Macungie, PA, USA) framed on a rigid, 3D-printed, polylactic acid (PLA) structure (see Fig. $3 \mathrm{~b}$ and $3 \mathrm{c}$ ). The membrane presents 8 holes to position fingers in different configuration. To have a continuous rehabilitation process, the device has a selectable stiffness, thanks to a resizing mechanism built in the frame (see Fig. 3d). HERO can work with the help of an external mobile app that guides the user through the exercises by means of a vocal command (imposing a different rhythm and number of repetitions for each exercise).

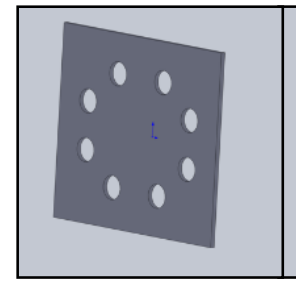

(a)

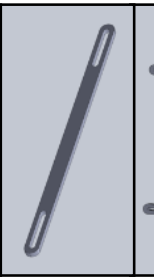

(b)

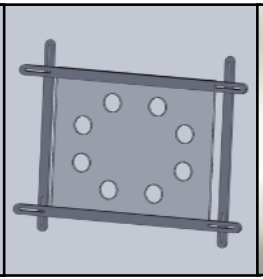

(c)

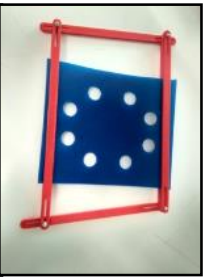

(d)
Figure 3. HERO prototype - (a) stretchable membrane; (b) frame component; (c) design of the prototype; (d) prototype

HERO was developed through a collaborative process, with 5 students, 3 mentors and input from clinicians according to the working flow described in Figure 2. UBORA was useful to compare the available products in the market in support of rehabilitation, and to investigate several device concepts to find the most comfortable solution to be developed as a prototype. Through WP1, according to the MDR 2017/745, the device was classified as a Class I (low risk) and the applicable basic safety standards, listed in Tab. 1, were provided after compilation of an appropriate regulation checklist.

TABLE I . REGULATION CHECKLIST PROVIDED BY UBORA EINFRASTRUCTURE FOR HERO

\begin{tabular}{|l|l|}
\hline \multicolumn{1}{|c|}{ Standard } & \multicolumn{1}{|c|}{ Description } \\
\hline $\begin{array}{l}\text { ISO 10993-1 and any of } \\
\text { the additional chapters of } \\
\text { this standard that may be } \\
\text { applicable to your } \\
\text { specific device }\end{array}$ & $\begin{array}{l}\text { NOTE: This standard has 18 } \\
\text { additional chapters, reading chapter } \\
-1 \text { will guide you on the choice of } \\
\text { the applicable additional chapters. }\end{array}$ \\
\hline EN ISO 13485:2016 & $\begin{array}{l}\text { This standard forifies } \\
\text { requirements for all entities }\end{array}$ \\
\hline
\end{tabular}

\begin{tabular}{|c|c|}
\hline & $\begin{array}{l}\text { involved in MDs, in all stages of the } \\
\text { product life cycle: from design to } \\
\text { manufacture to installation to } \\
\text { disposal. }\end{array}$ \\
\hline EN ISO 14971:2012 & $\begin{array}{l}\text { This standard specifies } \\
\text { requirements for designers and } \\
\text { manufacturers of MDs, in order to } \\
\text { minimize the risk of the device } \\
\text { itself. There is no "risk zero" device } \\
\text { but many activities can be } \\
\text { implemented to reduce and manage } \\
\text { risk. This standard provides useful } \\
\text { checklists and also guidance on the } \\
\text { most widespread risk management } \\
\text { techniques such as FMEA. }\end{array}$ \\
\hline $\begin{array}{l}\text { MEDDEV } 2.7 .1 \text { rev } 4 \\
\text { CLINICAL } \\
\text { EVALUATION: A } \\
\text { GUIDE FOR } \\
\text { MANUFACTURERS } \\
\text { AND NOTIFIED } \\
\text { BODIES UNDER } \\
\text { DIRECTIVES } \\
\text { 93/42/EEC and } \\
\text { 90/385/EEC } \\
\end{array}$ & $\begin{array}{l}\text { This guideline provides information } \\
\text { on methods used to assess the } \\
\text { clinical performance and the } \\
\text { clinical benefit of a MD. }\end{array}$ \\
\hline IEC 62366-1 & $\begin{array}{l}\text { This standard provides guidance on } \\
\text { how to manage the human factors } \\
\text { while designing a MD (usability } \\
\text { engineering). }\end{array}$ \\
\hline EN ISO 15223-1:2016 & $\begin{array}{l}\text { This standard lists a series of } \\
\text { symbols that may be applicable in } \\
\text { labels of MDs }\end{array}$ \\
\hline
\end{tabular}

As a consequence of the controlled design flow, HERO can be considered compliant with the MDR 2017/745 from the design point of view.

\section{USABILITY OF THE UBORA E-PLATFORM}

The usability of the UBORA e-infrastructure was tested during a workshop at the 4th WHO Global Forum on Medical Devices, held in Visakhapatnam, Andhra Pradesh, India, from 13th to 15 th December 2018 [24], where the UBORA project was presented.

After a brief introduction, workshop participants were assigned a clinical challenge and went through the collaborative development of a MD using UBORA. At the end of the workshop, participants were asked to complete a survey for obtaining their impressions regarding the usability of the einfrastructure considering their different backgrounds and knowledge. The aim was to understand the possible impacts that the use of UBORA can have on users coming from different countries and with dissimilar relevant legislation on MDs. Figure 4 shows a very positive perception from 10 workshop participants with typical sum responses valued with 4 and 5, in a 5-point Linkert scale, reaching percentages from $70 \%$ to $80 \%$.

The main focus of this workshop, other than demonstrating UBORA's ease of use, was to promote and push harmonization on MD legislation on the basis of the EU approach. 


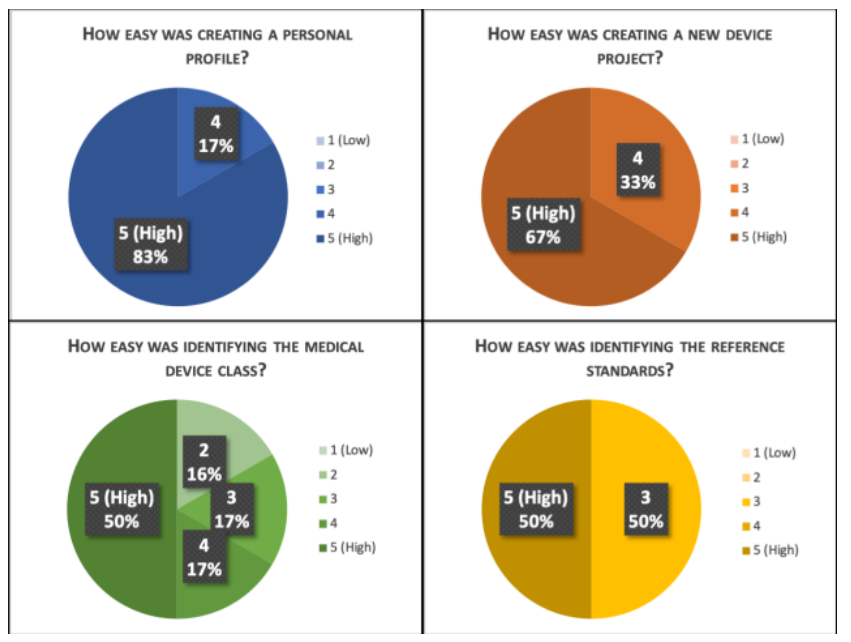

Figure 4 - Summary of results regarding workshop participants' opinion about the usability of the UBORA e-infrastructure

\section{CONCLUSION}

The UBORA e-infrastructure is a device design and learning tool for biomedical engineers. Its aim is to promote well-being for all, increasing access to MDs and moving towards global health equity in line with the United Nations Sustainable Development Goals.

Through UBORA, the biomedical community can develop and share blueprints, data, idea, clinal needs, results, and the basic safety requirements for respecting the QMS. If properly implemented, the devices designed with UBORA can be considered compliant to the MDR 2017/745 from the design point of view.

In recognition of its potential impact to global health, during the 4th WHO Global Forum on Medical Devices, UBORA was also presented during a Plenary session [25]. The WHO community has recognized UBORA as a user-friendly, versatile, and stable e-infrastructure for supporting the collaborative development of MDs, compliant with the current regulation. It has been underlined as a key resource for global action toward the democratization of medical technology.

\section{ACKNOWLEDGMENTS}

This project has received funding from the European Union's Horizon 2020 research and innovation programme under grant agreement $\mathrm{N}^{\circ} 731053$. We would like to express our appreciation to the students Omega Mitinda, Hugo Linder, Giorgio Bondì, Yenus Muhammed Erziku and Alice Giannotti, designers of HERO during the UBORA Design School 2018. Thanks also to their mentors, Prof. Juan Manuel Guijosa from Universidad Politécnica de Madrid (UPM), and Prof. Akinniyi Osuntoki from University of Lagos for their constructive suggestions during the planning and development stages. The identification of the clinical need by Andrés Díaz Lantada from UPM is acknowledged.

\section{REFERENCES}

[1] Sustainable Development Goals. [Online]. Available: https://www.un.org/sustainabledevelopment/sustainable-developmentgoals/ [retrieved: February 2019]
[2] World Health Organization. World health statistics 2016: monitoring health for the SDGs sustainable development goals. World Health Organization, 2016.

[3] World Health Organization. Medical devices: managing the mismatch: an outcome of the priority medical devices project. World Health Organization, 2010.

[4] Iadanza, E., and Dyro, J., "Clinical engineering handbook". Elsevier, 2004.

[5] World Health Organization. Barriers to innovation in the field of medical devices. Backgroud paper 6. Geneva, World Health Organization, 2010.

[6] Malkin, R. A. "Barriers for medical devices for the developing world" Expert review of medical devices, 4(6), 759-763, 2007.

[7] Malkin, R. A. "Design of health care technologies for the developing world." Annu. Rev. Biomed. Eng. 9 (2007): 567-587.

[8] Lustick, D. R., and Zaman, M. H., "Biomedical engineering education and practice challenges and opportunities in improving health in developing countries."Science and Innovation Policy, 2011 Atlanta Conference on. IEEE, 2011.

[9] Douglas, T. S., "Biomedical engineering education in developing countries: research synthesis." EMBC. IEEE, 2011.

[10] Ahluwalia, A., De Maria C., and Diaz Lantada, A., "The Kahawa Declaration: a manifesto for the democratization of medical technology." Global Health Innovation 1.1, 2018.

[11] Perens, B., "The open source definition." Open sources: voices from the open source revolution 1 (1999): 171-188.

[12] Williams, A., Gibb, A., and Weekly, D., "Research with a hacker ethos: what DIY means for tangible interaction research". Interactions, 19(2), 14-19, 2012.

[13] Niezen, G., Eslambolchilar, P., and Thimbleby H., "Open-source hardware for medical devices". BMJ innovations (2016): bmjinnov2015.

[14] Gamma Cardio Soft S.r.l. [Online]. Available: http://www.gammacardiosoft.it/openecg/ [retrieved: February 2019]

[15] Ferretti, J., Di Pietro, L., \& De Maria, C., "Open-source automated external defibrillator. HardwareX, 2, 61-70, 2017.

[16] Arcarisi, L.; Di Pietro, L.; Carbonaro, N.; Tognetti, A.; Ahluwalia, A.; De Maria, C. Palpreast-A New Wearable Device for Breast SelfExamination. Appl. Sci. 2019, 9, 381.

[17] De Maria, C., Mazzei, D., and Ahluwalia, A., "Improving African health care through open source Biomedical Engineering." International Journal on Advances in Life Sciences 7.1 2015:10-19.

[18] UBORA: Euro-Africa Open Biomedical Engineering Innovation eplatform for Innovation through Education. [Online]. Available: https://platform.ubora-biomedical.org/ [retrieved: February 2019].

[19] Ahluwalia, A., De Maria, C., Díaz Lantada, A., Di Pietro, L., Ferretti, J., Magliaro, C., et al. Open source technology in biomedical engineering: fast track towards sustainable development. In: "EMBEC \& NBC 2017. ISBN 978-981-10-5122-7. pp. 13. https://doi.org/10.1007/978-981-10-5122-7.

[20] European Medical Device Regulation 2017/745. [Online]. Available: https://eur-lex.europa.eu/legalcontent/EN/TXT/PDF/?uri=OJ:L:2017:117:FULL\&from=EN [retrieved: February 2019].

[21] Cheng, M., "Medical device regulations: global overview and guiding principles". World Health Organization, 2003.

[22] Lissel, A., Ottenberg, F., Bracio, B. R., Ravizza, A., De Maria, C., Ahluwalia, A., ... \& Trommler, P. (2016, August). Status and solutions to medical device regulations for improving the healthcare landscape in Africa. EMBC, 2016 IEEE, pp. 4329-4332. IEEE.

[23] International Organization of Standardization EN ISO 13485:2016 Medical devices - Quality management system- Requirements for regulatory purpose certification. [Online]. Available: https://www.iso.org/standard/59752.html [retrieved: February 2019].

[24] World Health Organization - Fourth Global Forum of Medical Devices.[Online].Available:https://www.who.int/medical_devices/glo bal_forum/4th_gfmd/en/ [retrieved: February 2019].

[25] World Health Organization - Fourth Global Forum of Medical Devices - Plenary Presentations - UBORA e-Infrastructure. [Online]. Available:https://www.who.int/medical_devices/global_forum/4th_gf md_plenary_presentations/en/index4.html [retrieved: February 2019]. 